\title{
A comparative study of the RuiBreath and NIOX VERO analyzers for detecting fractional exhaled nitric oxide
}

\author{
Yalan Liu ${ }^{1 \#}$, Xiaohong Chang ${ }^{1 \#}$, Lirong Liang ${ }^{2}$, Zhaoshen Hou ${ }^{1}$, Yong Lu ${ }^{1}$ \\ ${ }^{1}$ Department of Respiratory and Critical Care Medicine, Beijing Institute of Respiratory Medicine and Beijing Chao-Yang Hospital, Capital Medical \\ University, Beijing, China; ${ }^{2}$ Clinical Epidemiology and Tobacco Dependence Treatment Research Department, Beijing Institute of Respiratory \\ Medicine and Beijing Chao-Yang Hospital, Capital Medical University, Beijing, China \\ Contributions: (I) Conception and design: Y Lu; (II) Administrative support: Z Hou; (III) Provision of study materials or patients: X Chang, Z Hou; \\ (IV) Collection and assembly of data: Y Liu, X Chang; (V) Data analysis and interpretation: Y Liu, L Liang; (VI) Manuscript writing: All authors; (VII) \\ Final approval of manuscript: All authors. \\ "\#hese authors contributed equally to the present work. \\ Correspondence to: Yong Lu. Department of Respiratory and Critical Care Medicine, Beijing Institute of Respiratory Medicine and Beijing Chao-Yang \\ Hospital, Capital Medical University, No. 8 Gongti Nanlu, Chaoyang District, Beijing 100020, China. Email: luyong8764@sina.com.
}

\begin{abstract}
Background: Fractional exhaled nitric oxide (FeNO) measurement is a reliable, noninvasive marker of airway inflammation. Portable FeNO analyzers facilitate the assessment of airway inflammation in primary care. Differences between analyzers from different manufacturers are not comparable. Here, we aimed to compare the FeNO values obtained by a new portable device (RuiBreath, Guangzhou Ruipu Medical Technology Co., Ltd, Guangzhou, China) to those obtained by the widely used NIOX VERO portable analyzer (Aerocrine AB, Solna, Sweden) in patients with asthma.

Methods: This prospective validation study enrolled patients ( $\geq 14$ years old) with asthma over a 2 -month period (July and August 2019) at the Beijing Chao-Yang Hospital. At least one valid FeNO measurement was obtained using each analyzer for all the participants.

Results: There were 197 participants in this study. The FeNONIOX and FeNORuiBreath values significantly differed $(\mathrm{P}=0.016)$. After log-transformation, a difference was found only when the FeNONIOX was $<25 \mathrm{ppb}(\mathrm{P}<0.001)$. The FeNONIOX and FeNORuiBreath values had a significant correlation $(\mathrm{r}=0.938$, $\mathrm{P}<0.001$ ), which was confirmed by the Altman-Bland plot. Using a receiver-operating characteristic curve analysis, when using $49 \mathrm{ppb}$ as the cut-off point for the two devices in identifying patients with symptomatic asthma symptoms, the sensitivity and specificity were 0.42 and 0.88 , respectively, by NIOX, and 0.40 and 0.89 , respectively, by RuiBreath.
\end{abstract}

Conclusions: This is the first report of FeNO values obtained by the new portable RuiBreath FeNO analyzer. The FeNORuiBreath values are reliable and directly comparable with the FeNONIOX values.

Keywords: Exhaled nitric oxide; airway inflammation; asthma; NIOX VERO; RuiBreath

Submitted Jan 05, 2021. Accepted for publication Jun 23, 2021.

doi: $10.21037 /$ jtd-21-25

View this article at: https://dx.doi.org/10.21037/jtd-21-25

\section{Introduction}

Asthma is a chronic inflammatory disorder of the airways with bronchial hyperresponsiveness producing symptoms related to limited airflow that can be reversed $(1,2)$.
The worldwide prevalence of asthma varies from $4.2 \%$ in China to $11.6 \%$ in Sweden $(3,4)$. Asthma triggers include allergens, medications (particularly aspirin and nonsteroidal anti-inflammatory drugs), and environmental factors such as tobacco smoke and occupational exposure 
$(1,2)$. Complications include secondary bacterial or viral lower respiratory infections, chronic use of inhaled or oral glucocorticosteroids, respiratory failure, and, rarely, death $(1,2,5)$. Approximately $5-10 \%$ of patients do not respond well to standard treatments $(2,6,7)$. Increased mortality is observed in patients who require intubation, have a past history of severe disease, and have specific psychosocial factors $(2,6,7)$.

The detection of exhaled nitric oxide was first described in 1991 (8). After decades of development, now it is recognized as a simple and reliable noninvasive marker of airway inflammation in asthma (9-11). The American Thoracic Society (ATS) strongly recommends measuring the fraction of exhaled nitric oxide (FeNO) as a biomarker for the diagnosis and management of asthma (12), defining $50 \mathrm{ppb}$ as a high FeNO value (13). ATS clinical practice guidelines suggest that $\mathrm{FeNO} \geq 50 \mathrm{ppb}$ indicates eosinophilic inflammation and that symptomatic patients are likely to be responsive to corticosteroids (13). Another study found that symptomatic, untreated patients with high FeNO (cut-off value of $47 \mathrm{ppb}$ ) are more likely to exhibit responsiveness to inhaled steroid therapy (14). A high FeNO ( $>49 \mathrm{ppb})$ after 4 weeks of withdrawal of ICS therapy in asymptomatic patients suggest asthma relapse (15).

Other airway diseases such as allergic rhinitis $(16,17)$ and chronic cough are also associated with elevated FeNO levels (18).

An ideal FeNO analyzer should be portable, convenient, reliable with good testing repeatability, and inexpensive. NIOX VERO (Aerocrine AB, Solna, Sweden) is an electrochemical analyzer that has been approved by the US Food and Drug Administration for use in asthma management $(19,20)$. RuiBreath ${ }^{\mathrm{TM}}$ (Guangzhou Ruipu Medical Technology Co., Ltd, Guangzhou, China) is a new electrochemical analyzer approved by the Medical Product Administration of Guangdong province (China), but no published study has evaluated the reliability of the RuiBreath $^{\mathrm{TM}}$ device.

Therefore, this study aims to compare the results of FeNO from the two analyzers and to calculate their correlation and conversion equation in asthmatic patients $\geq 14$ years of age.

We present the following article in accordance with the STROBE reporting checklist (available at https://dx.doi. org/10.21037/jtd-21-25).

\section{Methods}

\section{Study design and participants}

This is a prospective validation study that enrolled patients ( $\geq 14$ years of age) considered with asthma over a 2-month period (July 2019 and August 2019) at the Asthma Outpatient Clinic of the Respiratory and Critical Care Medicine Department of Beijing Chao-Yang Hospital. The study was conducted in accordance with the Declaration of Helsinki (as revised in 2013). The study was approved by the China Ethics Committee of Registering Clinical Trial (ChiECRCT20190220). All subjects provided written informed consent.

Asthma was confirmed by a history of variable respiratory symptoms including wheezing, shortness of breath, and cough, accompanied by variable airflow limitation, either by forced expiratory volume in $1 \mathrm{~s}$ (FEV1) or by bronchial provocation test, according to the international guidelines (21). Those who were not confirmed as having asthma and who fulfilled the diagnostic criteria but with any acute respiratory infection were excluded. Cough variant asthma (CVA) was diagnosed when the cough is the only symptom of the asthmatic patient. When the FEV1 after airway reversibility experiment or inhaled corticosteroids (ICS) therapy was lower than the predicted $70 \%$, asthma and chronic obstructive pulmonary disease overlap (ACO) were diagnosed. Age, sex, inhalation treatment condition, and smoking habit were recorded from each patient. Symptoms and attack frequency of asthma were recorded. A patient with asthma attacks $>2$ times per week, or with night waking due to asthma or SABA reliever for symptoms more than twice/week, or any activity limitation due to asthma over the last 4 weeks was considered as symptomatic asthma. We ensured that all subjects followed the pretest instructions, i.e., no nitrate-rich foods or beverages, no tobacco smoking, and no exercise within $1 \mathrm{~h}$ preceding the test, to avoid interference with the test results. FeNO measurement was performed before the lung function test.

\section{FeNO measurement}

FeNO (unit of ppb) was measured according to the ATS/ European Respiratory Society (ERS) guidelines using a NIOX VERO electrochemical hand-held analyzer and a RuiBreath device (13). Twenty-five ppb was 


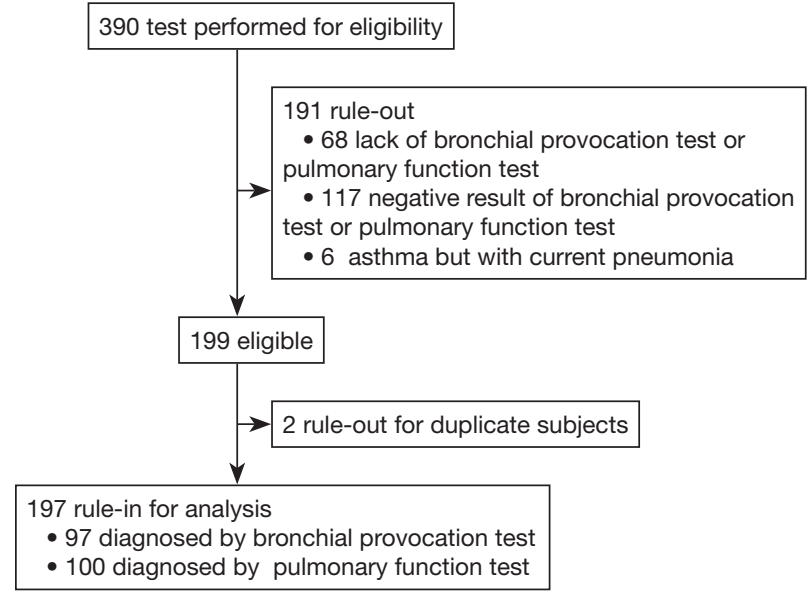

Figure 1 Flow diagram of the patient selection process.

taken as the cut-off value; lower than $25 \mathrm{ppb}$ indicated a low possibility of eosinophilic airway inflammation, while higher than $25 \mathrm{ppb}$ indicated a high possibility of eosinophilic airway inflammation. These two analyzers use electrochemical sensor technology for the detection of NO. Any gas that can be electrochemically oxidized or reduced can also be detected by means of an electrochemical sensor. The NIOX VERO test was performed before the RuiBreath test, with an interval of 0.5 hours between the two tests in order to reduce the potential confounders. The two devices were used strictly in accordance with their user manual. The algorithms of the two analyzers are similar. The subjects were asked to exhale into the device with a constant flow rate of $50 \mathrm{~mL} / \mathrm{s}$ sustained for $10 \mathrm{~s}$, and a single acceptable level was recorded for the test (22). Failure was recorded when the subject could not achieve an acceptable result within six attempts. Data from all valid FeNO measurements for all subjects were analyzed. Adverse events and serious injuries, including dyspnea, hemoptysis, and pneumothorax, were assessed during the measurements for each subject.

\section{Statistical analysis}

The distribution of the continuous variables was assessed using the Kolmogorov-Smirnov goodness-of-fit test. In order to normalize the distribution, FeNO data were logtransformed for analysis and reported as geometric mean \pm geometric stander error of the mean (GSEM). The other continuous variables are expressed as means \pm standard deviations, ratios, or medians $\left(25^{\text {th }}-75^{\text {th }}\right.$ percentile). The paired $t$-test was used for comparisons of Gaussiandistributed data. Wilcoxon's signed-rank test was performed for analysis of non-Gaussian-distributed data. Pearson's correlation coefficient ( $r$ ) and linear regression analysis were used to estimate the relationship between the two measurements. The Bland-Altman method was used to evaluate the agreement between the two devices. The receiver-operating characteristic (ROC) curve was applied to differentiate between patients with asymptomatic and symptomatic asthma for each device. The data analysis and ROC curves were performed with SPSS 16.0 (IBM, Armonk, NY, USA). The Bland-Altman plot and other figures were generated with GraphPad Prism 5 (Graphpad Software, San Diego, CA, USA). Two-sided P values $\leq 0.05$ were considered statistically significant.

\section{Results}

\section{Subject characteristics}

Figure 1 presents selection process. Both NIOX and RuiBreath FeNO were measured in all the 390 tests from 388 participants in the outpatient department. Among them, 191 participants did not fulfill the diagnostic criteria of asthma due to either lack of or negative result of a pulmonary function test or bronchial provocation test. Therefore, 197 patients are included in the final data analysis with a diagnosis of asthma according to the international guidelines (2), and all of these patients completed the two analyses. The mean age of the 197 patients was $49 \pm 15$ years, and 84 were males, 26 were current smokers, and 120 were receiving inhalation therapy with either budesonide/formoterol or salmeterol/fluticasone (Table 1). No adverse events and serious injuries were observed during the measurements by both analyzers.

\section{FeNO values}

The $\mathrm{FeNO}_{\mathrm{NIOX}}$ and $\mathrm{FeNO}_{\text {RuiBreath }}$ values differed significantly between the two devices \{NIOX, 28 [18-51] vs. 30 [21-50] ppb; $\mathrm{P}=0.016\}$ (Figure 2). When the $\mathrm{FeNO}_{\text {NIOX }}$ was $<100$, the $\mathrm{FeNO}_{\text {RuiBreath }}$ was slightly higher than the $\mathrm{FeNO}_{\text {NIOX }}$. When the $\mathrm{FeNO}_{\mathrm{NIOX}}$ was $>100$, the $\mathrm{FeNO}_{\text {RuiBreath }}$ tended to be slightly lower than the $\mathrm{FeNO}_{\mathrm{NIOX}}$ (Figure 3 and Table 2). After log-transformation, significant differences were observed between the $\mathrm{FeNO}_{\mathrm{NIOX}}$ and $\mathrm{FeNO}_{\text {RuiBreath }}$ values (29.94 \pm 1.06 vs. $32.90 \pm 1.05$ ppb, $\mathrm{P}<0.001$; Table 3). When data are divided into four groups according to the $\mathrm{FeNO}_{\mathrm{NIOX}}$ 
Table 1 Patient demographics

\begin{tabular}{lcc}
\hline & $\begin{array}{c}\text { Asthma } \\
(\mathrm{n}=197)\end{array}$ & $\begin{array}{c}\text { Rule-out } \\
\text { data }(\mathrm{n}=191)\end{array}$ \\
\hline $\begin{array}{l}\text { Age, mean } \pm \text { SD (median; } \\
\text { interquartile range) }\end{array}$ & $\begin{array}{c}49 \pm 15 \\
(50 ; 37-62)\end{array}$ & $\begin{array}{c}45 \pm 15 \\
(45 ; 33-58)\end{array}$ \\
$\begin{array}{l}\text { Gender (male/female) } \\
\text { Smoking history, n (\%) }\end{array}$ & $84 / 113$ & $78 / 113$ \\
Never smoked & $143(72.6)$ & $139(72.8)$ \\
Ex-smoker & $28(14.2)$ & $27(14.1)$ \\
Current smoker & $26(13.2)$ & $25(13.1)$ \\
Inhalation medication history, $\mathrm{n}(\%)$ & & \\
Under inhalation treatment & $120(60.9)$ & $28(14.7)$ \\
$\begin{array}{l}\text { Never use inhalation device } \\
\text { or stopped over 1 month ago }\end{array}$ & $77(39.1)$ & $163(85.3)$ \\
Diagnosis, n (\%) & & \\
Bronchial asthma & & - \\
Cough variant asthma & $137(69.5)$ & - \\
Asthma COPD overlap & $35(17.8)$ & - \\
\hline
\end{tabular}

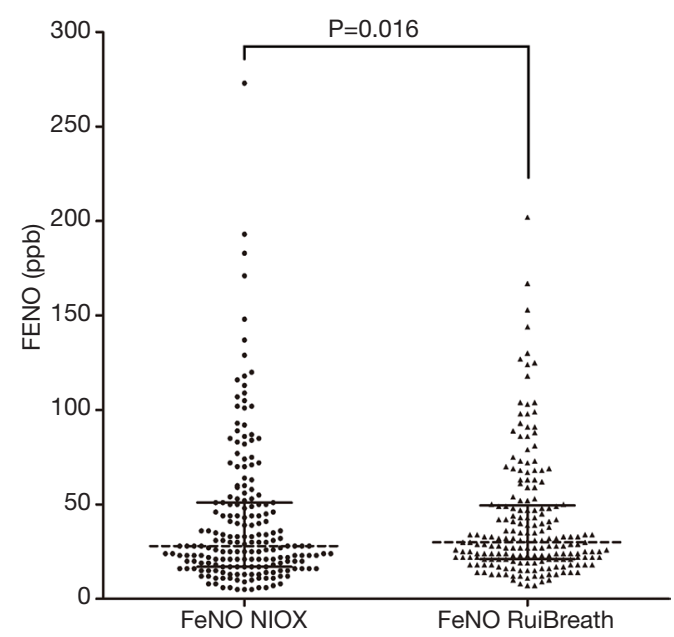

Figure 2 Scatter plot of the fraction of exhaled nitric oxide (FeNO) values obtained using the NIOX VERO and RuiBreath analyzers. Points represent the $\mathrm{FeNO}_{\mathrm{NIOX}}$ values, and triangles represent the $\mathrm{FeNO}_{\text {Ruibreath }}$ values. The solid lines and dotted lines represent the interquartile ranges and the medians, respectively.

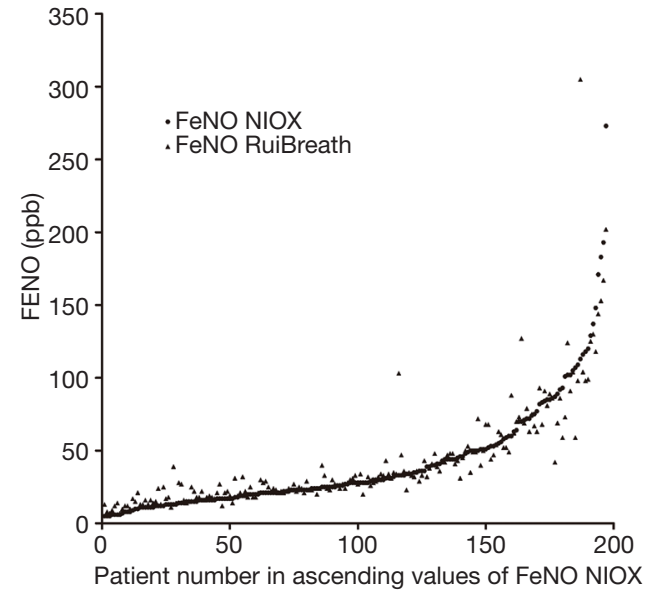

Figure 3 Point diagram of the pairwise distribution of the fraction of exhaled nitric oxide (FeNO) values measured by Ruibreath and NIOX VERO. The points represent the $\mathrm{FeNO}_{\mathrm{NIOX}}$ values, and the triangles represent the $\mathrm{FeNO}_{\text {Ruibreath }}$ values. The diagram was generated according to the increasing $\mathrm{FeNO}_{\text {NIOX }}$ values.

Table 2 Fraction of exhaled nitric oxide (FeNO) values detected by NIOX and RuiBreath devices

\begin{tabular}{lcccc}
\hline & $\mathrm{n}$ & NIOX & RuiBreath & P value \\
\hline ALL & 197 & $28[18-51]$ & $30[21-50]$ & 0.016 \\
FeNO $_{\text {NIOX }}<25$ & 85 & $16[12-21]$ & $20[15-24]$ & $<0.001$ \\
FeNO $_{\text {NIOX }} 25-49$ & 58 & $33[28-40]$ & $33[29-41]$ & 0.125 \\
FeNO $_{\text {NIOX }} 50-99$ & 37 & $64[53-83]$ & $67[51-77]$ & 0.456 \\
FeNO $_{\text {NIOX }} \geq 100$ & 17 & $118[106-160]$ & $118[98-149]$ & 0.017 \\
\hline
\end{tabular}

Data are presented as median (25th-75th percentile).

Table 3 Log-transformed fraction of exhaled nitric oxide (FeNO) values detected by NIOX and RuiBreath devices

\begin{tabular}{lcccc}
\hline & $\mathrm{n}$ & NIOX & RuiBreath & P value \\
\hline ALL & 197 & $29.94 \pm 1.06$ & $32.90 \pm 1.05$ & $<0.001$ \\
FeNO $_{\text {NIOx }}<25$ & 85 & $15.67 \pm 1.05$ & $18.46 \pm 1.04$ & $<0.001$ \\
FeNO $_{\text {NIOx }} 25-49$ & 58 & $33.08 \pm 1.03$ & $34.37 \pm 1.04$ & 0.180 \\
FeNO $_{\text {NIOx }} 50-99$ & 37 & $65.74 \pm 1.04$ & $63.91 \pm 1.05$ & 0.480 \\
FeNO $_{\text {NIOX }} \geq 100$ & 17 & $131.34 \pm 1.07$ & $119.84 \pm 2.53$ & 0.261 \\
\hline
\end{tabular}

Data are presented as geometric mean \pm GSEM. 

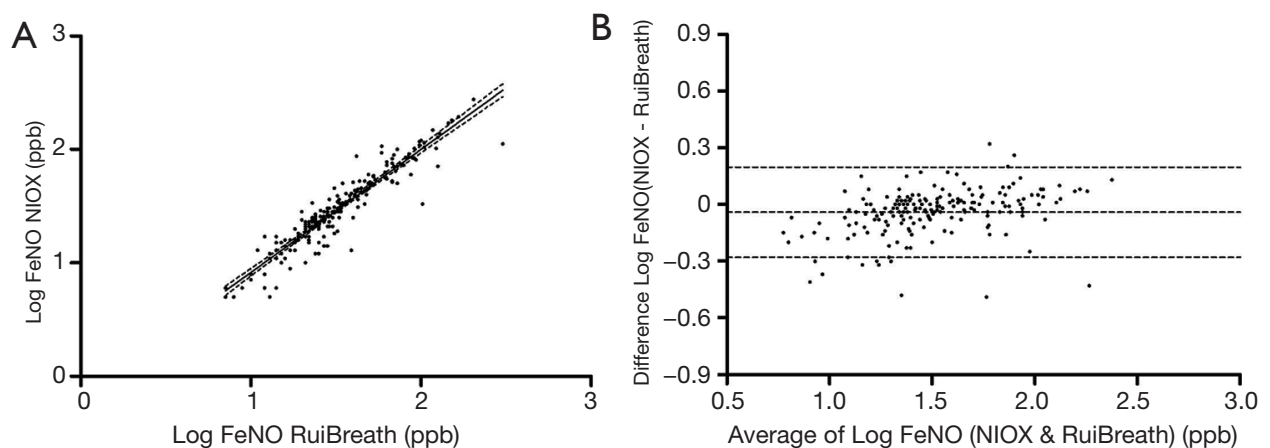

Figure 4 The fraction of exhaled nitric oxide (FeNO) value showed a significant correlation between the two analyzers. (A) Linear regression with 95\% confidence interval. (B) Altman-Bland plot (right panel) of the RuiBreath vs. NIOX VERO values in 197 asthmatic patients.

Table 4 Fraction of exhaled nitric oxide (FeNO) values detected by the NIOX and RuiBreath devices grouped by symptom status

\begin{tabular}{lcccc}
\hline & $\mathrm{n}$ & NIOX & RuiBreath & P value \\
\hline Symptomatic & 105 & $36.92 \pm 1.09$ & $40.64 \pm 1.08$ & $<0.001$ \\
Asymptomatic & 92 & $23.57 \pm 1.07$ & $25.84 \pm 1.06$ & 0.003 \\
\hline
\end{tabular}

Data are presented as geometric mean \pm GSEM.

values (group 1: <25; group 2: 25-49; group 3: 50-99; group $4: \geq 100 \mathrm{ppb}$ ), the differences between groups 2 and 3 , which is the interval of most interest among clinicians, were not statistically significant. In group 1 , the median value of $\mathrm{FeNO}_{\text {NIOX }}$ was lower than that of $\mathrm{FeNO}_{\text {RuiBreath }}\{16$ [12-21] vs. 20 [15-24] ppb; $\mathrm{P}<0.001\}$, and in group 4 , the median value of $\mathrm{FeNO}_{\text {NIOX }}$ was higher than that of $\mathrm{FeNO}_{\text {RuiBreath }}\{118$ [106-160] vs. 118 [98-149] ppb; $\mathrm{P}=0.017$; Table 2\}. After $\log$-transformation, the differences were significant only in group $1(15.67 \pm 1.05$ vs. $18.46 \pm 1.04 \mathrm{ppb} ; \mathrm{P}<0.001)$, but not in the other groups (all $\mathrm{P}>0.05$; Table 3).

\section{Correlation}

The FeNO value showed a significant correlation between the two analyzers $(\mathrm{r}=0.938, \mathrm{P}<0.001)$. The regression equation was $\log \mathrm{FeNO}_{\mathrm{NIOX}}=1.083(\mathrm{SE}=0.029)$ $\times \log \mathrm{FeNO}_{\text {RuiBreath }}-0.166\left(\mathrm{SE}=0.044, \mathrm{r}^{2}=0.880, \mathrm{P}<0.001\right.$; Figure $4 A$ ). The Bland-Altman plot shows a high degree of agreement between the two devices (Figure 4B).

\section{Asthma control status}

We tested the differences between the two devices among patients with different asthma control statuses. There were 105 participants with symptomatic asthma and 92 with asymptomatic asthma. The differences between the two devices were statistically significant in both the asymptomatic and symptomatic asthma groups (symptomatic asthma: $\mathrm{FeNO}_{\mathrm{NIOX}}, 36.92 \pm 1.09$ vs. $\mathrm{FeNO}_{\text {RuiBreath }}, 40.64 \pm 1.08 \mathrm{ppb}, \mathrm{P}<0.001$; asymptomatic asthma: $\mathrm{FeNO}_{\mathrm{NIOX}}, 23.57 \pm 1.07$ vs. $\mathrm{FeNO}_{\text {RuiBreath }}, 25.84 \pm 1.06$ ppb, $\mathrm{P}=0.003$; Table 4). Both $\mathrm{FeNO}_{\mathrm{NIOX}}$ and $\mathrm{FeNO}_{\text {RuiBreath }}$ values were significantly higher in patients with symptomatic asthma than in those with asymptomatic asthma $(\mathrm{P}=0.001$ and $\mathrm{P}<0.001$ for $\mathrm{FeNO}_{\mathrm{NIOX}}$ and $\mathrm{FeNO}_{\text {RuiBreath }}$, respectively).

\section{ROC analysis for symptomatic astbma}

Figure 5 shows the ROC curve for the $\mathrm{FeNO}_{\text {NIOX }}$ and $\mathrm{FeNO}_{\text {RuiBreath }}$ values in predicting symptomatic asthma. The area under curve (AUC) values are 0.661 (95\% CI: 0.585-0.736; $\mathrm{P}<0.001)$ and 0.680 (95\% CI: 0.606-0.754; $\mathrm{P}<0.001)$, respectively. Pairwise comparison of the ROC curves revealed non-significant differences in the AUC between the $\mathrm{FeNO}_{\text {NIOX }}$ and $\mathrm{FeNO}_{\text {RuiBreath }}(\mathrm{P}=0.727)$. The best cut-off value with the maximum Youden's index is 48.5 for $\mathrm{FeNO}_{\mathrm{NIOX}}$ (Youden's index of 0.299) and 30.5 for $\mathrm{FeNO}_{\text {RuiBreath }}$ (Youden's index of 0.292). The cut-off value with suboptimal Youden's index is 30.5 for $\mathrm{FENO}_{\mathrm{NIOx}}$ (Youden's index of 0.298 ) and 48.5 for $\mathrm{FENO}_{\text {RuiBeath }}$ (Youden's index of 0.291). When using $49 \mathrm{ppb}$ as the cutoff points for the two measurements, similar sensitivity and specificity are obtained ( $42 \%$ sensitivity and $88 \%$ specificity for $\mathrm{FeNO}_{\mathrm{NIOX}}$, and $40 \%$ sensitivity and $89 \%$ specificity for $\mathrm{FeNO}_{\text {RuiBreath }}$. 


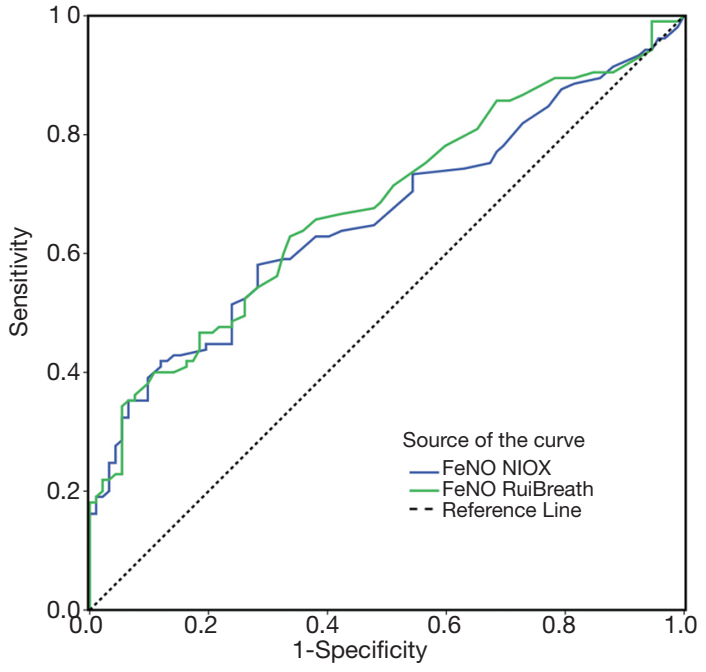

Figure 5 Receiver-operating characteristic (ROC) curve analysis was performed to differentiate between patients with asymptomatic and symptomatic asthma. The analysis included different cut-off points of the fraction of exhaled nitric oxide (FeNO) measurements obtained by NIOX (blue line) and RuiBreath (green line) in differentiating symptomatic asthma patients. The area under the curve (AUC) values of NIOX and RuiBreath measurements were $0.661(\mathrm{P}<0.001)$ and $0.680(\mathrm{P}<0.001)$, respectively.

\section{Discussion}

FeNO measurement is a reliable, noninvasive marker of airway inflammation (9-11). The use of portable FeNO analyzers may enable the assessment of airway inflammation in primary care. The RuiBreath is a novel device for FeNO measurement. Therefore, this study aimed to compare the FeNO values obtained by the RuiBreath device to the NIOX VERO device in asthmatic patients. This is the first report of FeNO values obtained by the new portable RuiBreath $\mathrm{FeNO}$ analyzer. The $\mathrm{FeNO}_{\text {RuiBreath }}$ values are reliable and directly comparable with the $\mathrm{FeNO}_{\mathrm{NIOX}}$ values. The results of the ROC analysis yielded an AUC of 0.680, with a sensitivity of $40 \%$ and a specificity of $89 \%$ at a cutoff value of $49 \mathrm{ppb}$. Based on these results, both FeNO devices are better suited to rule-in rather than to ruleout symptomatic asthma (RuiBreath: PPV $=80.8 \%$, NPV $=56.6 \%$; NIOXVero: $\mathrm{PPV}=80.0 \%, \mathrm{NPV}=57.0 \%$ ).

$\mathrm{FeNO}_{\text {RuiBreath }}$ values can be used to discriminate symptomatic asthma from asymptomatic asthma.

As recommended by the ATS/ERS guidelines (12), low FeNO values $(<25 \mathrm{ppb})$ suggest low eosinophilic inflammation, while high $\mathrm{FeNO}$ values $(>50 \mathrm{ppb})$ suggest a probable eosinophilic inflammation, and patients may respond well to corticosteroids. In this study, although the differences between the two analyzers are significant, further subgroup analysis shows non-significant differences in the interval of FeNO values between 25 and $100 \mathrm{ppb}$, which is the most important value interval in clinical application. After $\log$ transformation, the paired $t$-test for the $\log \mathrm{FeNO}$ values showed significant differences between the two devices. After stratification, the differences were only found to be significant in patients with $\mathrm{FeNO}_{\text {NIOX }}$ $<25 \mathrm{ppb}$ but not significant in patients with $\mathrm{FeNO}_{\mathrm{NIOX}}$ $\geq 25 \mathrm{ppb}$. Moreover, the overall difference of $\mathrm{FeNO}$ values between the two analyzers is around $2 \mathrm{ppb}$, and about $3 \mathrm{ppb}$

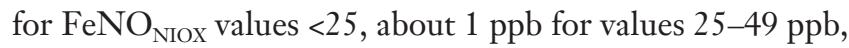
about $2 \mathrm{ppb}$ for values $50-99 \mathrm{ppb}$, and $12 \mathrm{ppb}$ for values $>100 \mathrm{ppb}$. This suggests that the performance of RuiBreath is comparable to that of NIOX VERO in patients with airway eosinophilic inflammation, and the differences seem not significant in clinical practice.

The FeNO values between the two devices were significantly correlated, as supported by the regression analysis. The Bland-Altman plot demonstrates agreement between the two devices, and, importantly, the differences between $\mathrm{FeNO}_{\text {RuiBreath }}$ and $\mathrm{FeNO}_{\mathrm{NIOX}}$ values showed no evident change with an increase in the FeNO. This finding confirmed that RuiBreath could be reliably used in any asthmatic patient irrespective of the degree of airway inflammation.

In this study, the capability of the two analyzers to discriminate symptomatic asthmatic patients from asymptomatic patients was examined. As expected, asymptomatic asthmatic patients had significantly lower FeNO values when compared with symptomatic asthma patients using both devices. Importantly, the magnitude of the difference was greater with the RuiBreath analyzer than with the NIOX.

In one study, Molino et al. evaluated the agreement among FeNO values measured by three different newly developed portable analyzers. They reported that the FeNO measurements obtained by these analyzers could differ to a clinically relevant extent and concluded that the devices could not be used interchangeably (23). In another study, Maniscalco et al. used different techniques to measure the $\mathrm{FeNO}$ value and found that differences between analyzers from different manufacturers could be resolved if the devices were calibrated properly. Although chemiluminescence is an emerging technique due to their rapid, sensitive, and highly selective measurement of NO, their high cost, non- 
portability, and the need to frequently calibrate the devices limit the applicability of chemiluminescence in a clinical research setting (24).

According to the ROC curve analysis, the sensitivity of the NIOX device was higher than that of RuiBreath, while the specificity of NIOX was lower than that of RuiBreath. The AUC value generated by RuiBreath was higher than that of NIOX, but the difference was not significant. Taken together, those findings suggest that the new RuiBreath device has a similar discriminating power compared with NIOX in differentiating symptomatic asthma from asymptomatic asthma. Similar results are also observed in the validation process of other FeNO devices like NOA280i and NOBreath (20,25-27).

In addition, in this cohort, participants with a $\mathrm{FeNO}_{\mathrm{NIOX}}$ or $\mathrm{FeNO}_{\text {RuiBreath }}$ value $\geq 49 \mathrm{ppb}$ have a higher likelihood of having symptomatic asthma. This cut-off value approximates that of the definition of a high $\mathrm{FeNO}$ value of $50 \mathrm{ppb}$ mentioned by the ATS guidelines (13). The ATS clinical practice guidelines suggest that $\mathrm{FeNO} \geq 50 \mathrm{ppb}$ indicates eosinophilic inflammation and that symptomatic patients are likely to be responsive to corticosteroids (13). Another study found that symptomatic, untreated patients with high FeNO (cut-off value of $47 \mathrm{ppb}$ ) are more likely to exhibit responsiveness to inhaled steroid therapy (14). A high FeNO ( $>49 \mathrm{ppb}$ ) after 4 weeks of withdrawal of ICS therapy in asymptomatic patients suggest asthma relapse (15). In this study, among 105 symptomatic asthma participants, 66 were untreated or withdrawing from ICS for more than 1 month, and 39 were on ICS treatment. In symptomatic participants, high FeNO with or without ICS treatment, persistent allergen exposure, poor adherence or inhaler technique, inadequate ICS dose, or allergic rhinitis should be considered. Nevertheless, the interpretation of high FeNO values should be cautious. The variation of FeNO values from a previous test may be more important in clinical practice, and the monitoring of personalized FeNO values over time may become a part of self-management in the future (28).

This study has several limitations. First, all participants were recruited from a single hospital. This suggests the presence of a selection bias. Second, lung function was not diagnosed in this study (and FEV1 and FEV1/VC cannot be presented), and the results are not up to the standard to diagnose acute airway inflammation. It might have led to a selection of sicker patients and thus might lead to an overestimation of the diagnostic accuracy. Third, currently, electrochemical analysis is the most commonly used detection method in clinical practice in China. There are differences between chemiluminescence and electrochemical analysis principles and detection methods, and other influencing factors may be introduced by using different principles as research. At present, our hospital is not equipped for performing chemiluminescence, and the use of this gold standard in clinical practice is limited. Finally, this was a real-life test, which was difficult to control all the subjects to follow the pre-test instructions; it was hard to know what the potential impact might be on the results. Additional prospective multicenter research is necessary to compare the FeNO values in asthmatic adolescents and patients with COPD and other types of airway diseases.

In conclusion, the FeNO values obtained using the novel RuiBreath device are in agreement with the values obtained using the NIOX VERO device, especially in the clinically relevant range of FeNO values (25-100 ppb). The predictive value in differentiating asymptomatic from symptomatic asthmatic patients by $\mathrm{FeNO}_{\text {RuiBreath }}$ was similar to that of $\mathrm{FeNO}_{\text {NIOX }}$. The new RuiBreath device is a reliable and convenient FeNO analyzer and is comparable to the NIOX VERO.

\section{Acknowledgments}

Funding: This work was supported by the China Soong Ching Ling Foundation Respiratory Disease Clinical Research Public Welfare Fund [2018MZF H-004].

\section{Footnote}

Reporting Checklist: The authors have completed the STROBE reporting checklist. Available at https://dx.doi. org $/ 10.21037 /$ jtd-21-25

Data Sharing Statement: https://dx.doi.org/10.21037/jtd-21-25

Conflicts of Interest: All authors have completed the ICMJE uniform disclosure form (available at https://dx.doi. org/10.21037/jtd-21-25). The authors have no conflicts of interest to declare.

Ethical Statement: The authors are accountable for all aspects of the work in ensuring that questions related to the accuracy or integrity of any part of the work are appropriately investigated and resolved. The study was conducted in accordance with the Declaration of 
Helsinki (as revised in 2013). The study was approved by the China Ethics Committee of Registering Clinical Trial (ChiECRCT20190220), and all patients gave their informed consent.

Open Access Statement: This is an Open Access article distributed in accordance with the Creative Commons Attribution-NonCommercial-NoDerivs 4.0 International License (CC BY-NC-ND 4.0), which permits the noncommercial replication and distribution of the article with the strict proviso that no changes or edits are made and the original work is properly cited (including links to both the formal publication through the relevant DOI and the license). See: https://creativecommons.org/licenses/by-nc-nd/4.0/.

\section{References}

1. British Thoracic Society and Scottish Intercollegiate Guidelines Network (BTS/SIGN) national clinical guideline on management of asthma (SIGN158). London: British Thoracic Society, 2019.

2. Global Initiative for Asthma (GINA) global strategy for asthma management and prevention. Fontana: Global Initiative for Asthma, 2020.

3. Huang K, Yang T, Xu J, et al. Prevalence, risk factors, and management of asthma in China: a national cross-sectional study. Lancet 2019;394:407-18.

4. Backman H, Hedman L, Jansson SA, et al. Prevalence trends in respiratory symptoms and asthma in relation to smoking - two cross-sectional studies ten years apart among adults in northern Sweden. World Allergy Organ J 2014;7:1.

5. National Asthma Education and Prevention Program. Expert Panel Report 3 (EPR-3): Guidelines for the Diagnosis and Management of Asthma-Summary Report 2007. J Allergy Clin Immunol 2007;120:S94-138. Erratum in: J Allergy Clin Immunol 2008;121:1330.

6. Higgins JC. The 'crashing asthmatic. Am Fam Physician 2003;67:997-1004.

7. Boulet LP. Influence of comorbid conditions on asthma. Eur Respir J 2009;33:897-906.

8. Gustafsson LE, Leone AM, Persson MG, et al. Endogenous nitric oxide is present in the exhaled air of rabbits, guinea pigs and humans. Biochem Biophys Res Commun 1991;181:852-7.

9. Kharitonov SA, Barnes PJ. Exhaled biomarkers. Chest 2006;130:1541-6.

10. Köhler D, Haidl P, Dellweg D. Inhaled corticosteroids and children. N Engl J Med 2006;355:624;author reply 625-6.

11. Karrasch S, Linde K, Rücker G, et al. Accuracy of FENO for diagnosing asthma: a systematic review. Thorax 2017;72:109-16.

12. Dweik RA, Boggs PB, Erzurum SC, et al. An official ATS clinical practice guideline: interpretation of exhaled nitric oxide levels (FENO) for clinical applications. Am J Respir Crit Care Med 2011;184:602-15.

13. American Thoracic Society; European Respiratory Society. ATS/ERS recommendations for standardized procedures for the online and offline measurement of exhaled lower respiratory nitric oxide and nasal nitric oxide, 2005. Am J Respir Crit Care Med 2005;171:912-30.

14. Smith AD, Cowan JO, Brassett KP, et al. Exhaled nitric oxide: a predictor of steroid response. Am J Respir Crit Care Med 2005;172:453-9.

15. Pijnenburg MW, Hofhuis W, Hop WC, et al. Exhaled nitric oxide predicts asthma relapse in children with clinical asthma remission. Thorax 2005;60:215-8.

16. Gratziou C, Rovina N, Makris M, et al. Breath markers of oxidative stress and airway inflammation in Seasonal Allergic Rhinitis. Int J Immunopathol Pharmacol 2008;21:949-57.

17. Rolla G, Guida G, Heffler E, et al. Diagnostic classification of persistent rhinitis and its relationship to exhaled nitric oxide and asthma: a clinical study of a consecutive series of patients. Chest 2007;131:1345-52.

18. Kowal K, Bodzenta-Lukaszyk A, Zukowski S. Exhaled nitric oxide in evaluation of young adults with chronic cough. J Asthma 2009;46:692-8.

19. Silkoff PE, Carlson M, Bourke T, et al. The Aerocrine exhaled nitric oxide monitoring system NIOX is cleared by the US Food and Drug Administration for monitoring therapy in asthma. J Allergy Clin Immunol 2004;114:1241-56.

20. Harnan SE, Tappenden P, Essat M, et al. Measurement of exhaled nitric oxide concentration in asthma: a systematic review and economic evaluation of NIOX MINO, NIOX VERO and NObreath. Health Technol Assess 2015;19:1-330.

21. Bateman ED, Hurd SS, Barnes PJ, et al. Global strategy for asthma management and prevention: GINA executive summary. Eur Respir J 2008;31:143-78.

22. Halbert RJ, Tinkelman DG, Globe DR, et al. Measuring asthma control is the first step to patient management: a literature review. J Asthma 2009;46:659-64.

23. Molino A, Fuschillo S, Mosella M, et al. Comparison of three different exhaled nitric oxide analyzers in chronic 
respiratory disorders. J Breath Res 2019;13:021002.

24. Maniscalco M, Vitale C, Vatrella A, et al. Fractional exhaled nitric oxide-measuring devices: technology update. Med Devices (Auckl) 2016;9:151-60.

25. Tanabe $Y$, Harada N, Ito J, et al. Difference between two exhaled nitric oxide analyzers, NIOX VERO(®) electrochemical hand-held analyzer and NOA280i(®) chemiluminescence stationary analyzer. J Asthma 2019;56:167-72.

26. Endo Y, Shirai T, Akamatsu T, et al. Comparison of

Cite this article as: Liu Y, Chang X, Liang L, Hou Z, Lu Y. A comparative study of the RuiBreath and NIOX VERO analyzers for detecting fractional exhaled nitric oxide. J Thorac Dis 2021;13(7):4418-4426. doi: 10.21037/jtd-21-25 fractional exhaled nitric oxide levels measured using the NIOX VERO and NOA 280i. Ann Allergy Asthma Immunol 2017;119:383-5.

27. Inoue $Y$, Sato S, Manabe T, et al. Measurement of Exhaled Nitric Oxide in Children: A Comparison Between NObreath ${ }^{\circledR}$ and NIOX VERO ${ }^{\circledR}$ Analyzers. Allergy Asthma Immunol Res 2018;10:478-89.

28. Shaw DE. FeNO monitoring to adjust treatment in asthma: has it come of age? Thorax 2018;73:1095-6. 